\title{
VEGFC antibody therapy drives differentiation of AML
}

Running title; VEGFC targeted differentiation therapy in AML

Kim R. Kampen ${ }^{1,5}$, Frank J.G. Scherpen ${ }^{1}$, Hasan Mahmud ${ }^{1}$, Arja ter Elst ${ }^{1}$, André B. Mulder ${ }^{3}$, Victor Guryev ${ }^{2}$, Han J.M.P. Verhagen ${ }^{4}$, Kim De Keersmaecker ${ }^{5}$, Linda Smit ${ }^{4}$, Steven M. Kornblau $^{6}$, Eveline S. J. M. De Bont ${ }^{1 *}$

1. Division of Pediatric Oncology/Hematology, Department of Pediatrics, Beatrix Children's Hospital, University Medical Center Groningen, University of Groningen, Groningen, The Netherlands. 2. European Research Institute for the Biology of Ageing, University Medical Center Groningen, University of Groningen, Groningen, the Netherlands. 3. Department of Laboratory Medicine, University Medical Center Groningen, Groningen, the Netherlands. 4. Department of Hematology, VU University Medical Center, Cancer Center Amsterdam, Amsterdam, The Netherlands 5. Laboratory for disease mechanisms in cancer, Department of Oncology, KU Leuven, University of Leuven, Leuven Cancer Institute (LKI), Leuven, Belgium 6. Department of Leukemia The University of Texas M.D. Anderson Cancer, Houston, TX, United States of America.

* Corresponding author: Eveline de Bont, MD, PhD, Professor in Pediatric Oncology/Hematology, Head division of Pediatric Oncology/Hematology, Division of Pediatric Oncology, Department of Pediatrics, Beatrix Children's Hospital, University Medical Center Groningen, University of Groningen PO Box 30.001, 9700 RB Groningen, the Netherlands. E-mail: edebont@elkerliek.nl, fax: +31 50 3611671 , tel +31503614213.

Manuscript word count: 3559, abstract word count: 105, Figures: 4, Supplementary figures: 5, Supplementary tables: 3. 
Author Manuscript Published OnlineFirst on September 5, 2018; DOI: 10.1158/0008-5472.CAN-18-0250

Author manuscripts have been peer reviewed and accepted for publication but have not yet been edited.

VEGFC antibody therapy drives differentiation of $A M L$

\section{Abstract}

High expression of vascular endothelial growth factor C (VEGFC) predicts adverse prognosis in acute myeloid leukemia (AML). We therefore explored VEGFC targeting efficacy as an AML therapy using a VEGFC monoclonal antibody. VEGFC antibody therapy enforced myelocytic differentiation of clonal CD34+ AML blasts. Treatment of CD34+ AML blasts with the antibody reduced expansion potential by $30-50 \%$ and enhanced differentiation via FOXO3A suppression and inhibition of MAPK/ERK proliferative signals. VEGFC antibody therapy also accelerated leukemia cell differentiation in a systemic humanized AML mouse model. Collectively, these results define a regulatory function of VEGFC in CD34+ AML cell fate decisions via $\mathrm{FOXO} 3 \mathrm{~A}$ and serve as a new potential differentiation therapy for $\mathrm{AML}$ patients.

Keywords: Leukemia, VEGFC, AML, FOXO3A, differentiation therapy 
Author Manuscript Published OnlineFirst on September 5, 2018; DOI: 10.1158/0008-5472.CAN-18-0250

Author manuscripts have been peer reviewed and accepted for publication but have not yet been edited.

VEGFC antibody therapy drives differentiation of $A M L$

\section{Significance}

41 Findings reveal VEGFC targeting as a promising new differentiation therapy in AML. 
Author Manuscript Published OnlineFirst on September 5, 2018; DOI: 10.1158/0008-5472.CAN-18-0250

Author manuscripts have been peer reviewed and accepted for publication but have not yet been edited.

VEGFC antibody therapy drives differentiation of $A M L$

\section{Introduction}

Vascular Endothelial Growth Factor C (VEGFC) is one of the VEGF family members with a unique role in lymphangiogenesis as well as in angiogenesis in normal homeostasis and cancer.(1-4) VEGFC can bind to kinase insert domain receptor (KDR, i.e. VEGFR-2) and fms-related tyrosine kinase-4 (FLT-4, i.e. VEGFR-3) receptors expressed by vascular endothelial cells, lymphatic endothelial cells, and by leukemic blasts.(1-3, 5, 6) KDR is expressed extracellular on the acute myeloid leukemia (AML) cell membrane, intracellular in the cytoplasm and on the nuclear membrane of AML cells, while FLT-4 mainly stains positive within the cytoplasm of AML blasts.(5-7) This phenomenon implicates that the extrinsic VEGFC/KDR axis is more likely to support AML cells due to the limited availability of FLT-4 in these AML cells.

High VEGFC levels were identified as an independent prognostic factor in AML and associated with decreased complete remission rates and a reduced survival.(8) Exogenous VEGFC can protect AML cells from chemotherapy induced apoptosis.(5) We previously showed that endogenous VEGFC expression is associated with decreased drug responsiveness in childhood AML.(9) We therefore hypothesized that VEGFC is an important autocrine growth factor involved in CD34+ AML blast maintenance.

Current literature supports an important function for VEGFC in AML progression and therapy resistance. $(5,8,9)$ Nevertheless, the downstream mechanism of VEGFC signaling in AML blasts is still unknown, and its potential as therapeutic target in AML is an unexplored field of research. Therefore, we set out to investigate the contribution of VEGFC on AML cell functions and the associated downstream signal transduction regulation. 
Author Manuscript Published OnlineFirst on September 5, 2018; DOI: 10.1158/0008-5472.CAN-18-0250

Author manuscripts have been peer reviewed and accepted for publication but have not yet been edited.

VEGFC antibody therapy drives differentiation of $A M L$

\section{Methods}

AML patient samples Medical Ethical Committee approved METC 2010.036 and 2013.281, UMCG the Netherlands. After obtained written informed consent (according the declaration of Helsinki), patient samples were handled as was previously described.(7) Table S1 includes $A M L$ patient characteristics as FAB, karyotype, blast (\%), VEGFC levels (pg/mL), KDR (\%), FLT-4 (\%), CD34 (\%), and FLT3 mutational status.

Cell lines THP-1 and OCI AML3 AML cells were obtained from the American Type Culture Collection (ATCC and DSMZ), cultured in RPMI-1640 medium (Thermo Fisher) supplemented with $1 \%$ penicillin/ streptomycin (Thermo Fisher) and $10 \%$ fetal calf serum (FCS, Bodinco). MS5 bone marrow stromal feeder layer (a kind gift from J.J. Schuringa from the Dept. Experimental Hematology, University Medical Center Groningen). Cell lines were all tested mycoplasma free and $\sim 25$ times passaged. Cell line karyotypes were regularly tested and were maintained among passages.

Cloning lentiviral vectors shRNA sequences targeting VEGFC, VEGFR-2/KDR (Supp. Table S2) were genetically modified into a pLKO1-mCherry vector and PCR amplified FOXO3A was cloned into the pRRL-GFP vector. Lentiviral particles were generated by 293T cells using psPAX2, pMD2.G (VSV-G) and FuGENE (Roche).

Flow cytometry Cells were serum blocked, stained with primary antibodies and secondary antibodies (Table S2). Intracellular stainings were performed according to manufacturer's protocol (Fix \& Perm, Life Technologies). Annexin V-FITC(/PI) staining for apoptosis following manufacturer's protocol (Annexin-V-FLUOS staining kit, Roche). Samples were analyzed using LSRII (BD FACS DIVA software, BD bioscience) and FlowJo software (Tree Star Inc.).

VEGFC enzyme-Linked ImmunoSorbent Assay (ELISA) The VEGFC protein expression in patient samples was measured in duplicates using a VEGFC ELISA (R\&D Systems) following manufacturers protocol. 
VEGFC antibody therapy drives differentiation of $A M L$

Compounds VGX-100 is a human monoclonal VEGFC antibody (a kind gift from Vegenics Pty Ltd). VGX-100 binds to and precipitates all forms of VEGF-C in both the human and mouse.

CD34+ short-term and long-term culture assays CD34+ cells were isolated using a MoFlo-XDP sorter (Beckman Coulter). After CD34 sorting, the CD34 percentages exceeded 95\% in all samples. Human short-term Colony-Forming Cell (CFC) assay. A total of 1000 CD34+ sorted MNCs were cultured for 2 weeks in $1 \mathrm{~mL}$ methylcellulose (MethoCult $\circledast$ H4435 Enriched, Stem cell technologies) according to manufacturer's protocol, experiment is performed in duplicate per patient sample. Long-term culture-initiating cell (LTC-IC) assay. CD34+ sorted blasts are cultured on MS5 mouse bone marrow stromal cells, in Gartner's media; aMEM (Thermo Fisher) containing 12.5\% FCS, $12.5 \%$ horse serum (Thermo Fisher), 1\% penicillin/streptomycin, $57.2 \mu \mathrm{M} \beta$-mercaptoethanol (Sigma-Aldrich), and $1 \mu \mathrm{M}$ hydrocortisone (Sigma-Aldrich), supplemented with $20 \mathrm{ng} / \mathrm{mL}$ trombopoietin (TPO, a kind gift from Kirin Brewery), IL-3 (Gibco), and granulocyte colony-stimulating factor (GCSF, Invitrogen), experiment is performed in duplicate per patient sample. LTC-IC assay in limiting dilution. LTC-IC assay plated at a density range $(1 / 5 / 10 / 50 / 100 / 250 / 40.000 / 120.000$ cells/well) were subjected to CFC methylcellulose on top of the stroma (MS5) at week 5 of co-culturing. Experiment is performed in 10-plo per density per patient sample.

Microscopy Cytospins were stained with May-Grunwald-Giemsa (MGG). Images were taken with a Leica DM 3000 or Leica DM IL microscope with a Leica DFC420C camera (Leica Geosystems B.V.). Histological analysis of the sternum (bone marrow) and spleens of AML xenografted mice was outsourced to the Histology Core Facility of VIB, Leuven.

Western Blot (WB) Cells were lysed in Laemmli sample buffer (Bio-rad). Proteins were separated by sodium dodecyl sulphate-polyacrylamide gel electrophoresis, transferred to nitrocellulose membranes, and incubated overnight with primary antibodies (Table S2), 
Author Manuscript Published OnlineFirst on September 5, 2018; DOI: 10.1158/0008-5472.CAN-18-0250

Author manuscripts have been peer reviewed and accepted for publication but have not yet been edited.

VEGFC antibody therapy drives differentiation of $A M L$

washed, and incubated with HRP conjugated secondary antibodies. Protein bands were visualized by chemiluminescence. Phospho-proteome array (R\&D systems) analysis was performed according to manufacturer's protocol and data analysis and normalisation was performed as previously described.(7)

FLT3-ITD fragment analysis Fluorescent labeling technology and fragment length analysis to establish the ratio of the mutant (ITD) FLT3 allele to the wild type (WT) FLT3 allele. Ratios up to 0.5 are indicative for a heterozygous FLT3-ITD mutant allele present in $100 \%$ of the AML cells ( 1 ITD peak/ ( 1 ITD peak +1 WT peak $)=0.5)$. Newly diagnosed patients with AML harbor a heterozygous FLT3-ITD mutation in $>92 \%$ of the cases.(10)

Reversed Phase Protein Array (RPPA) Proteomic profiling was performed using newly diagnosed pediatric AML samples $(n=31)$ and CD34+ NBM samples $(n=10)$ using RPPA, as described previously.(11)

Quantitative Real-Time polymerase chain reaction ( $q R T-P C R$ ) FOXO3A, CD11b, and p21 mRNA expression together with HPRT as a reference gene were analyzed in triplicates using SYBR Green qRT-PCR (Bio-rad laboratories, Veenendaal, The Netherlands). Relative mRNA expression from triplicates was determined using the $\Delta \Delta \mathrm{Ct}$ method (primer sequences Table S2).

AML xenografted in NOD-SCID/IL2Y广 (NSG) mice NSG mice were purchased from Charles River. This animal study was approved by the ethical animal committee at $\mathrm{KU}$ Leuven (P262/2015). Animals received anti-VEGFC $40 \mathrm{mg} / \mathrm{kg}$ treatment twice a week via i.p. injections. Animals were injected with $10^{6}$ primary AML cells i.v. White blood cell counts were measured using a micro-semi CRP hematology analyzer (Axonlab).

Statistics Statistical package for the social science (SPSS 17) software was used for graphing box-plots. Mann-Whitney $U$ test was used to determine differences between AML and NBM or two experimental groups of mice, two-tailed Student's t-tests or a paired sample t-test were used for analysis comparing untreated and treated AML cells based upon 
Author Manuscript Published OnlineFirst on September 5, 2018; DOI: 10.1158/0008-5472.CAN-18-0250

Author manuscripts have been peer reviewed and accepted for publication but have not yet been edited.

VEGFC antibody therapy drives differentiation of $A M L$

143 Levene's test for equality of variance, Kruskal-Wallis test was used to define significant

144 differences between more than two groups.

145 
Author Manuscript Published OnlineFirst on September 5, 2018; DOI: 10.1158/0008-5472.CAN-18-0250

Author manuscripts have been peer reviewed and accepted for publication but have not yet been edited.

VEGFC antibody therapy drives differentiation of $A M L$

\section{Results}

\section{The VEGFC/KDR axis is selectively expressed by AML blasts}

VEGFC is an important prognostic factor in AML supporting AML blast growth and apoptosis evading signals (Figure S1A/B/C). The CD34+ and CD34- cell populations within primary AML patients samples expressed significantly higher levels of VEGFC as compared to NBM controls (Figure 1A, Kruskall-Wallis test, $P=0.013$ ). Associated to higher VEGFC expression, primary $\mathrm{AML}$ patient samples present elevated KDR membrane protein expression levels (Figure 1A, Mann-Whitney $U$ test, $P=0.001$ ), while FLT-4 membrane protein expression was absent (Fig 1A, Mann-Whitney $U$ test, $P=0.381) .(7)$ In support of these data, VEGFC and KDR knockdown effects on the proliferation of AML cell lines was comparable (Figure S2A). Cell cycle inhibitor p21 mRNA expression was significantly induced in anti-VEGFC treated as well as VEGFC knockdown AML cells (Figure S2B). Additionally, VEGFC supporting effects on AML cell growth were suppressed in KDR knockdown cells (Figure S2C). These findings, challenged us to explorer VEGFC (30 $\mu \mathrm{g} / \mathrm{mL})$ monoclonal antibody treatment effects on AML cell functions (Figure 1B).

\section{VEGFC antibody therapy eliminates the expansion potential of CD34+ AML cells by} enforcing myelocytic differentiation

In KDR expressing AML cell line THP-1, VEGFC antibody therapy significantly induced myelocytic differentiation, supported by an increased population of cells that express differentiation markers CD11b and CD14 (Figure 1C/D and S3A, Student's t-test, both $P<$ 0.05). Additionally, VEGFC antibody therapy induced apoptosis in a dose-dependent matter (Figure 1E). VEGFC antibody therapy reduced KDR membrane expression, which implicates an eradication of the VEGFC/KDR axis in these leukemic cells (Figure 1F). 
Author Manuscript Published OnlineFirst on September 5, 2018; DOI: 10.1158/0008-5472.CAN-18-0250

Author manuscripts have been peer reviewed and accepted for publication but have not yet been edited.

VEGFC antibody therapy drives differentiation of $A M L$

Next, VEGFC antibody therapy effects on CD34+ primary AML samples (Figure S3B/C) was examined in a variety of AML stem/progenitor cell assays. Colony forming cell assays (CFC assay, 3D semi-solid media) highlight a $25 \%$ reduction in four AML patient samples and one AML patient sample showed decreased colony formation solely after serial re-plate (Figure 2A, combining all performed CD34+ AML patient CFC assays, Mann-Whitney $U$ test, $P=$ 0.0192). VEGFC antibody therapy suppressive colony formation was supported by $35 \%$ lower total CFC cell counts in all AML samples (Figure 2A, Mann-Whitney $U$ test, $P=$ 0.0028). In long-term culture initiating cells assays (LTC-IC, 3D co-culture assay), VEGFC antibody therapy decreased the outgrowth of CD34+ AML cells in 6 out of the 7 AML patient samples, overall reducing the LTC-IC outgrowth by $28 \%$ (Figure 2B, Mann-Whitney U test, $P$ $=0.003)$. Although LTC-IC assays outgrowth was reduced by VEGFC antibody therapy, LTC-IC cultures were retained in the presence of VEGFC antibody therapy. Limiting dilution LTC-IC assays revealed a further decrease up to $49 \%$ in the CD34+ initiating leukemic cell outgrowth potential in the presence of anti-VEGFC (Figure 2C/D, Mann-Whitney $U$ test, $P=$ 0.003). Morphological analysis revealed VEGFC antibody therapy induced myelocytic differentiation that appeared already after one week of treatment (Figure 2E/F).

Besides an overall $28 \%$ reduction in the outgrowth of VEGFC antibody treated CD34+ AML blasts, a significant 3.3-fold induction of differentiation along the myelocytic lineage could be appreciated in LTC-IC assays (Figure 2G, Mann-Whitney $U$ test, $P=0.001$ ). Differentiation marker analysis confirmed that increasing percentages of cells stained positive for CD38, CD11b and CD14 or CD15 cells in liquid cultures, CFC assays and LTC-IC assays as compared to untreated controls (Figure $2 \mathrm{H}$ and S3D/E), while CD34 percentages were decreased. In addition, VEGFC antibody treated cultures presented increased percentages of apoptotic cells (Figure 2I and S3D). 
Author Manuscript Published OnlineFirst on September 5, 2018; DOI: 10.1158/0008-5472.CAN-18-0250

Author manuscripts have been peer reviewed and accepted for publication but have not yet been edited.

VEGFC antibody therapy drives differentiation of $A M L$

VEGFC antibody therapy targeted myelomonocytic differentiation of the leukemic clone

FLT3-ITD fragment analysis showed identical ratios of heterozygous FLT3-ITD mutant cells in untreated and VEGFC antibody treated cultures in CFC and LTC-IC assays (Table S3), supporting that anti-VEGFC treatment affects the leukemic clone. While the FLT3-ITD leukemic cells were affected by VEGFC antibody enforced myelomonocytic differentiation, the cellular responses for FLT3-WT AML samples were superior to the FLT3-ITD AML samples (Figure S4A, Mann-Whitney U test, $P=0.042$ ). VEGFC antibody therapy of control CD34+ NBM cultures presented an approximate 3-4 weeks latency in myelocytic lineage skewing as compared to AML CD34+ cells (Figure S4B/C). Overall, these findings highlight that VEGFC antibody treatment is a novel new differentiation therapy, which targets the leukemic clonogenic capacity of CD34+ AML blasts.

VEGFC antibody therapy targeted downstream $\mathrm{MEK}_{1 / 2} / \mathrm{Erk}_{1 / 2}$ phosphorylation in AML blasts

As a first approach to define VEGFC downstream targets, we analyzed phospho-proteome arrays of three independent untreated and VEGFC antibody treated AML samples. Phosphorylation of $\mathrm{MEK}_{1 / 2}$ (S218/S222, S222/S226), AMPKa2 (T172), HSP27 (S78/S82), Paxillin (Y118), STAT2 (Y689), and STAT5 ${ }_{\mathrm{b}}$ (Y699) were significantly reduced in anti-VEGFC treated AML samples (Figure $3 \mathrm{~A}$, paired samples t-test, mean $\pm \mathrm{SEM},{ }^{*} P<0.05$ ). Decreased phosphorylation of specifically $\mathrm{ERK}_{1 / 2}$ was confirmed by immunoblot analysis, and STAT5 $a / b$ was reduced in some cases in anti-VEGFC treated CD34+ AML samples, and not in CD34+ NBM (Figure 3B, Mann-Whitney $U$ test, $P=0.008$ for Erk, and $P=0,151$ for STAT5). In the previously performed LTC-IC assays in limiting dilutions, we observed a loss of erythropoiesis in some but not all AML patient samples, which is supported by reduced

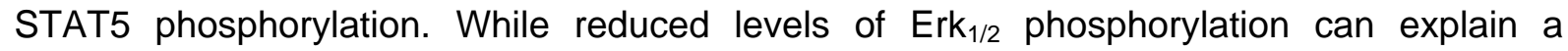


VEGFC antibody therapy drives differentiation of $A M L$

potential drop in expansion potential of the AML blasts by VEGFC antibody therapy, these findings cannot explain the induction of myelomonocytic differentiation.(7)

\section{VEGFC antibody therapy induced myelomonocytic differentiation via FOXO3A suppression}

Next, we combined flow cytometry VEGFC and KDR protein expression analysis together with reverse phase protein array (RPPA) analysis of the same set of pediatric AML samples. The VEGFC/KDR protein association network showed strong significant overlapping correlations for CCND3, LGALS3, FOXO3 (S318/321), PRKCD (S645), KIT, LSD1, NPM1, EIF2AK2, PTPN11, SSBP2, STAT5A/B (Figure 3C, Pearson correlations, all $P<0.05$ ).

FOXO3 suppression is described to mediate differentiation of the AML blasts.(12) In line with previous reports in adult AML samples, the basal and phosphorylated FOXO3A protein expression levels were significantly increased in pediatric AML as compared to CD34+ NBM samples (Figure S4D, Student's t-test, both $P<0.001$ ).(13) Immunoblot and flow cytometry analysis, revealed that FOXO3A protein expression was decreased upon VEGFC antibody treatment in THP-1 cells and primary AML samples (Figure 3D). To define whether VEGFC antibody therapy induced myelomonocytic differentiation was facilitated via its suppression of FOXO3A, we generated THP-1 FOXO3A overexpression cells. Constitutive FOXO3A overexpression was shown to rescue the anti-VEGFC induced expression of CD11b in a dose-dependent manner (Figure 3E and S4E/F, Student's t-test, $30 \mu \mathrm{g} / \mathrm{mL} P=0.027$ and 60 $\mu \mathrm{g} / \mathrm{mL} P=0.019$ ). These findings implicate that anti-VEGFC induced differentiation of leukemic cells was enforced via the suppression of FOXO3A.

VEGFC antibody therapy reduced splenic AML infiltration and induced myelomonocytic differentiation in an AML xenograft animal model 
To investigate the in vivo VEGFC targeting efficacy, we injected a primary AML patient sample (EVI1 ASXL1) into NSG mice that progressively developed leukemia's. These patient-derived AML xenografted mice were treated with DMSO or VEGFC antibody therapy. Leukemia was presented by increased white blood cell (WBC) counts in the peripheral blood of these animals. The WBC counts were significantly reduced by VEGFC antibody therapy (Figure 4A, Mann-Whitney $U$ test, $P=0.014$ ). Upon disease progression, histological bone marrow examination showed that the human AML blast population was only slightly reduced in VEGFC antibody treated animals (Figure 4B/S5, Mann-Whitney $U$ test, $P=0.127$ ). In the bone marrow, we observed a significant induction of eosiniphilic compartment in VEGFC antibody treated mice, supported by elevated levels of human CD11b expression (Figure 4B/C, Mann-Whitney $U$ test, histology $P=0.046$ and flow cytometry $P=0.007)$. The spleens of VEGFC antibody treated human PDX AML mice showed a minor decrease in size (Figure 4D). When focusing on spleen infiltration of human xenografted AML cells, histological examinations revealed a significant reduction in the amount of AML blasts that localized to the spleens in VEGFC antibody treated mice (Figure 4D/S5, Mann-Whitney $U$ test, $P=$ 0.011). The overall in vivo efficacy of VEGFC antibody treatment was characterized by a modest reduction in human PDX AML blast homing to the bone marrow of NSG mice, leading to a stronger decrease in human PDX AML engraftment to secondary AML sites as the spleen, where we observed a $\sim 50 \%$ reduction of human AML blasts. Taken together, this in vivo study shows that VEGFC antibody therapy suppresses the AML progression in vivo via the induction of differentiation. 
Author Manuscript Published OnlineFirst on September 5, 2018; DOI: 10.1158/0008-5472.CAN-18-0250

Author manuscripts have been peer reviewed and accepted for publication but have not yet been edited.

VEGFC antibody therapy drives differentiation of $A M L$

\section{Discussion}

VEGFC has been shown to be an independent prognostic factor and showed to interfere with AML survival in vivo and ex vivo. $(5,8,9)$ Our study highlights VEGFC targeted treatment as potential new differentiation therapy in AML. This study is one of the few that showed potent differentiation of the CD34+ leukemic clone by VEGFC targeting antibody therapy in vitro and in vivo. The modest VEGFC antibody therapy mediated reduction of AML blasts in the bone marrow of NSG mice in vivo underscores the supportive therapeutic potential of VEGFC targeting differentiation therapy in addition to conventional treatment regimens for $\mathrm{AML}$ patients. ATRA is a differentiation therapy available as conventional therapy in the clinic, applied to all acute promyelocytic leukemia (APL) patients that harbor the PML-RARA fusion protein. This differentiation therapy significantly improved the outcome of APL.(14, 15) More recently, the IDH2 inhibitor Enasidenib was approved in the clinics as new differentiation therapy of IDH2 mutant AMLs.(16)

VEGFC targeting antibody therapy is currently under investigation in a phase I clinical trial in combination with Bevacizumab (VEGFA targeting antibody) for advanced solid tumors using a maximum dosage of $20 \mathrm{mg} / \mathrm{kg}$, which showed to be well tolerated (NCT01514123) and final results should be available soon. VEGFC targeting antibody therapy in mice was previously shown using daily dosages $20 \mathrm{mg} / \mathrm{kg}$, which was well tolerated. $(17,18)$ In our study, VEGFC targeting antibody therapy at $40 \mathrm{mg} / \mathrm{kg}$ twice weekly in NSG mice did not affect the animal body weight nor showed aberrant histology of organs, and was therefore well tolerated.

Notably, we found that VEGFC antibody treatment blocked the erythroid outgrowth of 2 out of 5 patient samples in long-term CD34+ AML cultures, which can be caused by the inhibition of STAT5 phosphorylation that is known to guide erythropoiesis. $(19,20)$ Evidence of similar effects should be paid attention to in the ongoing clinical trial of this compound. The VEGFC targeting therapeutic approach might be useful for other cancer subtypes as well, as for 
Author Manuscript Published OnlineFirst on September 5, 2018; DOI: 10.1158/0008-5472.CAN-18-0250

Author manuscripts have been peer reviewed and accepted for publication but have not yet been edited.

VEGFC antibody therapy drives differentiation of $A M L$

example high VEGFC expression levels have been shown to modulate the breast cancer metastasizing capacity.(4)

Our study describes that VEGFC mediated FOXO3A levels are important for the preservation of immature AML blasts. Interactions between AMPKa2 and FOXO3A have previously been described.(21) We speculate that the decreased levels of AMPKa2 protein phosphorylation by VEGFC antibody treatment may be the key substrate for FOXO3A to control AML cell fate. So far, our findings indicate an important regulatory function for VEGFC in CD34+ AML cell fate decisions. Anti-VEGFC therapy enforced CD34+ AML blast myelocytic differentiation by FOXO3A suppression, creating new opportunities for differentiation therapy besides high dose chemotherapy in AML.

\section{Acknowledgements}

We thank Megan E. Baldwin and Robert Klupacs from Vegenics for their generous supply of anti-VEGFC treatment reagent (VGX-100). We thank Kirin Brewery for providing TPO used in LTC-IC assays. Henk Moes, Roelof Jan van der Lei and Geert Mesander assisted in cell sorting. J.J. Schuringa provided the MS5 feeder cell line. We thank Bart-Jan Wierenga for the lentiviral shRNA plasmid. The authors would like to thank the patients who donated leukemia specimens; nurse practitioners, and clinicians who acquired specimens. The authors thank Hein Schepers for sharing the FOXO3A overexpression plasmid.

\section{Funding support}

K.R. Kampen was supported by a PhD grant from the Foundation for Pediatric Oncology Groningen, the Netherlands (SKOG, 12001), animal experiments were granted by Foundation Beatrix Children's Hospital (2014 to K.R. Kampen), a subsequent grant was 
Author Manuscript Published OnlineFirst on September 5, 2018; DOI: 10.1158/0008-5472.CAN-18-0250

Author manuscripts have been peer reviewed and accepted for publication but have not yet been edited.

VEGFC antibody therapy drives differentiation of $A M L$

318 received from the Jan Kornelis de Cock Stichting (project code 2015-43 to K.R. Kampen), 319 and a postdoctoral fellowship was received from Lady Tata Memorial Trust International 320 Award for research in Leukaemia (2016-2017). A. ter Elst and H. Mahmud shared the KiKa 321 grant for the kinomics/proteomics AML project (2010-57 to E.S.J.M. de Bont and S.M. 322 Kornblau).

323

324 There is no conflict of interests according this manuscript. The authors declare no competing 325 financial interests regarding this manuscript. 
Author Manuscript Published OnlineFirst on September 5, 2018; DOI: 10.1158/0008-5472.CAN-18-0250

Author manuscripts have been peer reviewed and accepted for publication but have not yet been edited.

VEGFC antibody therapy drives differentiation of $A M L$

Reference List

1. Cao Y., Linden P., Farnebo J., Cao R., Eriksson A., Kumar V. et al. Vascular endothelial growth factor C induces angiogenesis in vivo. Proc. Natl. Acad. Sci. 1998; 95: 14389-14394.

2. Chien M.H., Ku C.C., Johansson G., Chen M.W., Hsiao M., Su J.L. et al. Vascular endothelial growth factor-C (VEGF-C) promotes angiogenesis by induction of COX-2 in leukemic cells via the VEGF-R3/JNK/AP-1 pathway. Carcinogenesis 2009; 30: 2005-2013.

3. Hamada K., Oike Y., Takakura N., Ito Y., Jussila L., Dumont D.J. et al. VEGF-C signaling pathways through VEGFR-2 and VEGFR-3 in vasculoangiogenesis and hematopoiesis. Blood 2000; 96: 3793-3800.

4. Skobe M., Hawighorst T., Jackson D.G., Prevo R., Janes L., Velasco P. et al. Induction of tumor lymphangiogenesis by VEGF-C promotes breast cancer metastasis. Nat. Med. 2001; 7: 192-198.

5. Dias S., Choy M., Alitalo K., and Rafii S. Vascular endothelial growth factor (VEGF)-C signaling through FLT-4 (VEGFR-3) mediates leukemic cell proliferation, survival, and resistance to chemotherapy. Blood 2002; 99: 2179-2184.

6. Fielder W., Graeven U., Ergun S., Verago S., Kilic N., Stockschläder M. et al. Expression of FLT4 and its ligand VEGF-C in acute myeloid leukemia. Leukemia 1997; 11: 1234-1237.

7. Kampen K.R., ter Elst A., Mahmud H., Scherpen F.J., Diks S.H., Peppelenbosch M.P. et al. Insights in dynamic kinome reprogramming as a consequence of MEK inhibition in MLL-rearranged AML. Leukemia 2014; 28: 589-599.

8. de Jonge,H.J., Valk,P.J., Veeger,N.J., ter Elst A., den Boer M.L., Cloos J. et al. High VEGFC expression is associated with unique gene expression profiles and predicts adverse prognosis in pediatric and adult acute myeloid leukemia. Blood 2010; 116: 1747-1754.

9. de Jonge H.J., Weidenaar A.C., ter Elst A., Boezen H.M., Scherpen F.J., Bouma-Ter Steege J.C. et al. Endogenous vascular endothelial growth factor-C expression is associated with decreased drug responsiveness in childhood acute myeloid leukemia. Clin. Cancer Res. 2008; 14: 924-930.

10. Schnittger S., Bacher U., Kern W., Alpermann T., Haferlach C., and Haferlach T. Prognostic impact of FLT3-ITD load in NPM1 mutated acute myeloid leukemia. Leukemia 2011; 25: 1297-1304.

11. Kornblau S.M., Tibes R., Qiu, Y.H., Chen W, Kantarjian H.M., Andreeff M. et al. Functional proteomic profiling of AML predicts response and survival. Blood 2009; 113: 154164.

12. Sykes S.M., Lane S.W., Bullinger L., Kalaitzidis D., Yusuf R., Saez B. et al. AKT/FOXO signaling enforces reversible differentiation blockade in myeloid leukemias. Cell 2011; 146: 697-708. 
Author Manuscript Published OnlineFirst on September 5, 2018; DOI: 10.1158/0008-5472.CAN-18-0250

Author manuscripts have been peer reviewed and accepted for publication but have not yet been edited.

VEGFC antibody therapy drives differentiation of $A M L$

14. Tallman M.S., Andersen J.W., Schiffer C.A., Appelbaum F.R., Feusner J.H., Ogden A. et al. All-trans-retinoic acid in acute promyelocytic leukemia. N. Engl. J. Med. 1997: 337: 1021-1028.

15. Fenaux P., Le Deley M.C., Castaigne S., Archimbaud E., Chomienne C., Link H. et al. Effect of all transretinoic acid in newly diagnosed acute promyelocytic leukemia. Results of a multicenter randomized trial. European APL 91 Group. Blood 1993; 82: 3241-3249.

16. Stein E.M., DiNardo C.D., Pollyea D.A., Fathi A.T., Roboz G.J., Altman J,K. et al. Enasidenib in mutant-IDH2 relapsed or refractory acute myeloid leukemia. Blood 2017; 130: 722-731.

17. Goyal S., Chauhan S.K., and Dana R. Blockade of prolymphangiogenic vascular endothelial growth factor $C$ in dry eye disease. Arch Ophthalmol. 2012; 130: 84-89.

18. Hajrasouliha A.R., Funaki T., Sadrai Z., Hattori T., Chauhan S.K., Dana R. Vascular endothelial growth factor-C promotes alloimmunity by amplifying antigen-presenting cell maturation and lymphangiogenesis. Invest Ophthalmol Vis Sci. 2012 53: 1244-50.

19. Shimizu R., Engel J.D., and Yamamoto M. GATA1-related leukaemias. Nat. Rev. Cancer 2008; 8: 279-287.

20. Wierenga A.T., Vellenga E., and Schuring J.J. Down-regulation of GATA1 uncouples STAT5-induced erythroid differentiation from stem/progenitor cell proliferation. Blood 2010; 115: 4367-4376.

izu R., Engel J.D., and Yamamoto M. GATA1-related leukaemias. Nat. Rev. Cancer 2008; 8: 279-287.

21. Banko M.R., Allen J.J., Schaffer B.E., Wilker E.W., Tsou P., White J.L., et al. Chemical genetic screen for AMPKa2 substrates uncovers a network of proteins involved in mitosis. Mol Cell. 2011 44: 878-92. 
Author Manuscript Published OnlineFirst on September 5, 2018; DOI: 10.1158/0008-5472.CAN-18-0250

Author manuscripts have been peer reviewed and accepted for publication but have not yet been edited.

VEGFC antibody therapy drives differentiation of $A M L$

397

398

399

400

401

402

403

404

405

406

407

408

409

410

411

412

413

414

415

416

417

418

419

420

421

422

\section{Figure legends}

Figure 1. VEGFC targeted therapy in AML.

(A) VEGFC protein expression analysis using enzyme-linked immunosorbent assay on normal bone marrow (NBM, $n=4)$ cells, CD34- AML cells $(n=3)$ and CD34+ AML cells $(n=5)$. Flow cytometry KDR (VEGFR-2) membrane protein expression levels of pediatric AML blasts $(n=60)$ and NBM $(n=5)$ controls. FLT4 (VEGFR-3) membrane protein expression levels on pediatric AML blasts $(n=18)$ and NBM $(n=5)$ controls. Box-plots show the median and error bars define data distribution. (B) VEGFC targeting study approach to identify the molecular mechanism of action. (C) May-Grunwald-Giemsa (MGG) staining of THP-1 cells in the presence or absence of VEGFC targeting human antibody (30 $\mu \mathrm{g} / \mathrm{mL})$. (D) CD11b and CD14 membrane protein expression by flow cytometric analysis of THP-1 untreated and antiVEGFC treated cells (mean \pm SEM). (E) Flow cytometric dose-dependent apoptosis analysis of anti-VEGFC treated THP-1 cells using annexin $V$ staining (mean \pm SEM). (F) Flow cytometric KDR membrane protein expression analysis upon VEGFC targeting antibody treatment in THP-1 cells (mean \pm SEM). Statistical analysis * $p$-value $<0.05$.

\section{Figure 2. VEGFC targeting therapy effects on CD34+ AML stem and progenitor cells.}

(A) Colony forming cell (CFC) assay analysis of CD34+ pediatric AML cells using a single dose of VEGFC antibody treatment representing the number CFC colonies on the left and the total CFC cell counts on the right $(n=6)$. (B) CD34+ AML expansion potential in long-term colony forming cell assay (LTC-IC) after 7 weeks of AML culturing on a mouse stromal feeder layer $(n=7)$. (C) CD34+ AML expansion potential of cobblestone forming cells residing underneath the stromal layer after 5 weeks of culturing, measured in limiting dilutions by their CFC output potential ( $n=5$ ). (D) CFC, LTC-IC and LTC-IC in limiting dilution represented per AML patient sample. (E) Representative MGG stained cytospins of untreated VEGFC antibody treated CD34+ AML samples in CFC and LTC-IC assays. (F) Microscopic 
VEGFC antibody therapy drives differentiation of $A M L$

quantification of AML cell culture composition after LTC-IC assays analysis comparing untreated and anti-VEGFC treated cultures $(n=7)$. (G) Box-plot presenting the mean percentage of myelomonocytic cells quantified from MGG stained cytospins comparing untreated and anti-VEGFC treated cultures. (H) Flow cytometry confirmation of anti-VEGFC induced myelomonocytic differentiation in CD34+ AML CFC and LTC-IC assays by CD38, CD34, CD11b and CD14 membrane protein expression analysis. (I) Flow cytometric annexin V/PI apoptosis analysis of untreated and anti-VEGFC treated CD34+ AML CFC and LTC-IC cultures. All box-plots represent the median and error bars define data distribution. Statistical analysis * $p$-value $<0.05$.

Figure 3. Identification of anti-VEGFC targeting mechanisms in pediatric AML and potential bypass mechanism.

(A) Phospho-protein array analysis presented as VEGFC antibody targeting effects relative to untreated control CD34+ AML samples $(n=3)$ (mean \pm SEM). (B) Immunoblot confirmation of anti-VEGFC treatment effects on MAPK/Erk, and STAT5 protein expression and phosphorylation in pediatric CD34+ AML samples, CD34+ NBM controls and THP-1 cells. Left: immunoblots. Right: combined quantification of the presented immunoblots. Box-plots show the median and error bars define data distribution. (C) Flow cytometry VEGFC and KDR protein expression analysis combined with RPPA array analysis in CD34+ pediatric AML samples. The Venn diagram shows significantly overlapping protein expression. Bold proteins show a positive correlation and non-bold proteins presented a negative correlation. All shown proteins were analyzed by RPPA analysis except the ones that are described to be analyzed by flow cytometry. (D) FOXO3A immunoblot analysis of THP-1 cells treated for 72h with anti-VEGFC. Intracellular protein expression as measured by flow cytometry analysis of 24h anti-VEGFC treated primary AML samples and THP-1 cells. (E) Scrambled control vector and FOXO3A constitutive overexpressing THP-1 cells in the presence or absence of 
Author Manuscript Published OnlineFirst on September 5, 2018; DOI: 10.1158/0008-5472.CAN-18-0250

Author manuscripts have been peer reviewed and accepted for publication but have not yet been edited.

VEGFC antibody therapy drives differentiation of $A M L$

VEGFC antibody treatment, analyzed for CD11b membrane protein expression levels measured using flow cytometry analysis (mean \pm SEM). Statistical analysis * $p$-value $<0.05$.

Figure 4. VEGFC antibody therapy induced differentiation in a primary AML xenografted animal model.

(A) The white blood cell (WBC) counts in the peripheral blood of mice injected with a primary EVI1 ASXL1 AML sample comparing DMSO with VEGFC antibody treated animals. (B/D) Histological analyses was performed on bone marrow and spleens of disease progressed animals using a semi-quantitative scoring system e.g. $0=$ no infiltration, $1<25 \%$ infiltration, $2=25-75 \%$ infiltration, $3>75 \%$ infiltration. DMSO treated animals were compared to VEGFC antibody treated animals. (B) Left: box-plot presents the AML blast infiltration in the bone marrow. Right: box-plot shows the infiltration of the AML derived eosinophilic compartment in bone marrow. (C) The box-plot represents flow cytometric analysis showing the percentage of human CD11b membrane protein expression in the bone marrow of the AML xenografted mice with on the right side the flow cytometry plots of the individual mice. (D) Left: spleen lengths. Middle: histological analysis of the AML blast infiltration in the spleen. Right: AML derived eosinophilic compartment in the spleen. All box-plots represent the median and error bars define data distribution. Statistical analysis * $p$-value $<0.05$. 

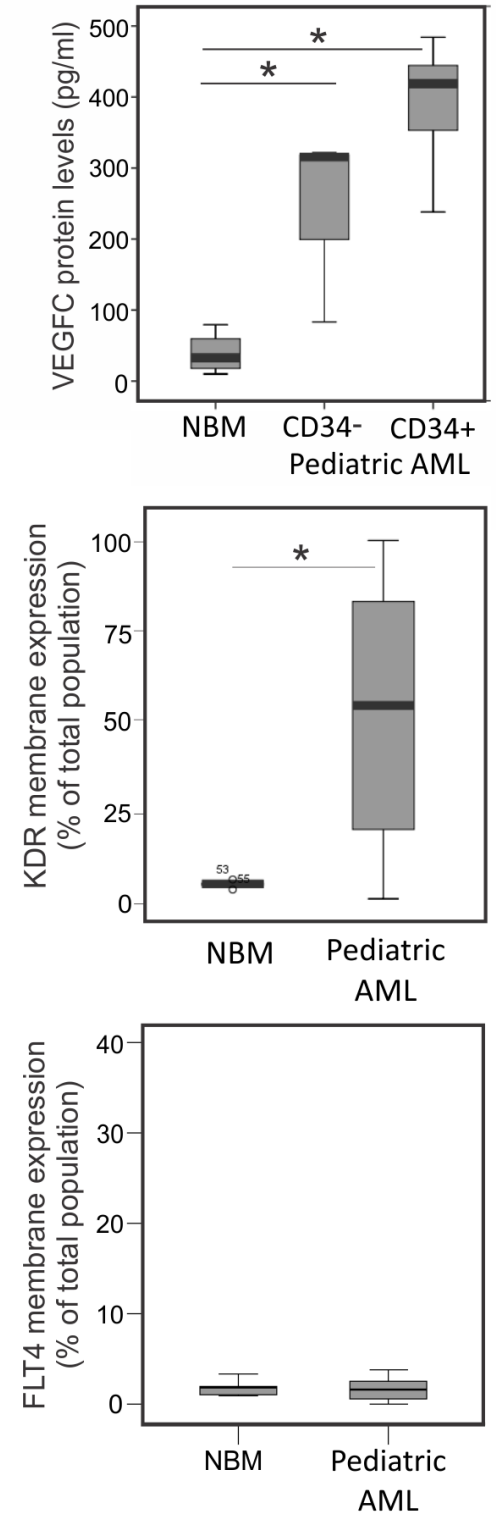

B

\section{Study design VEGFC as therapeutic target in AML}

AML cell lines

CD34

primary AML cells

CD34

NBM cells
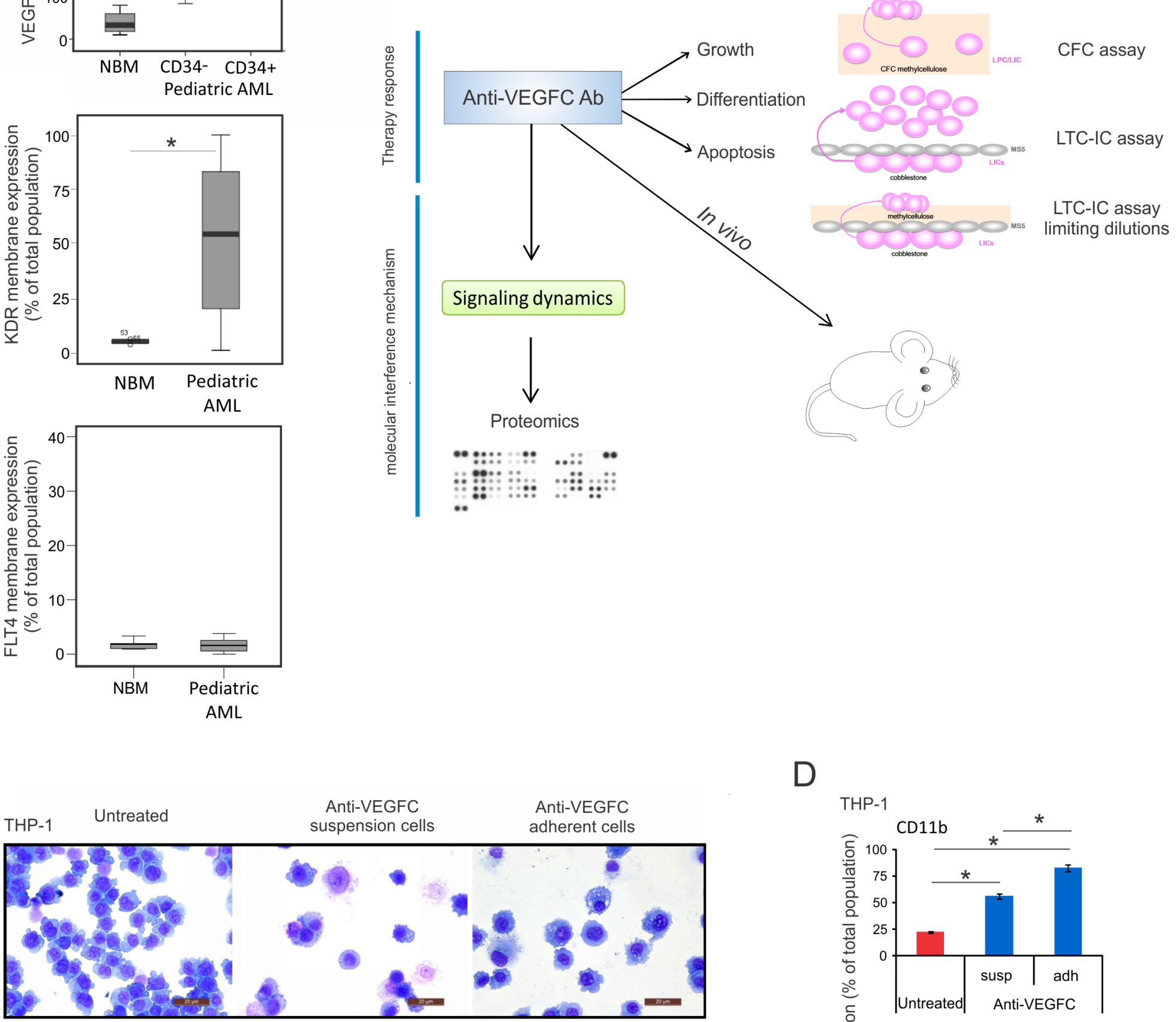

$E$

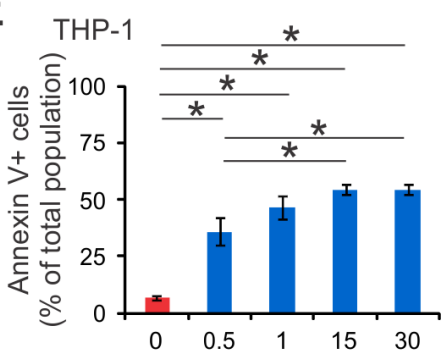

F

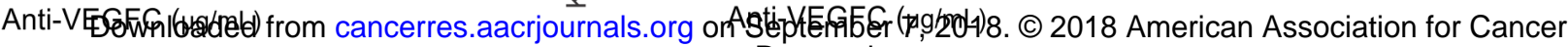
Research.

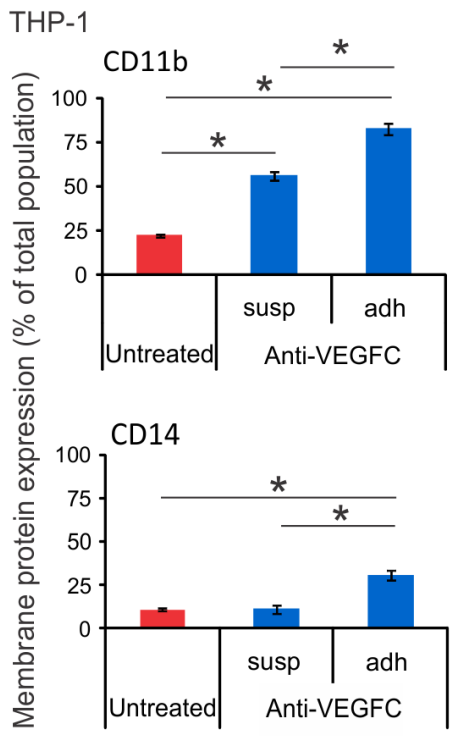


A

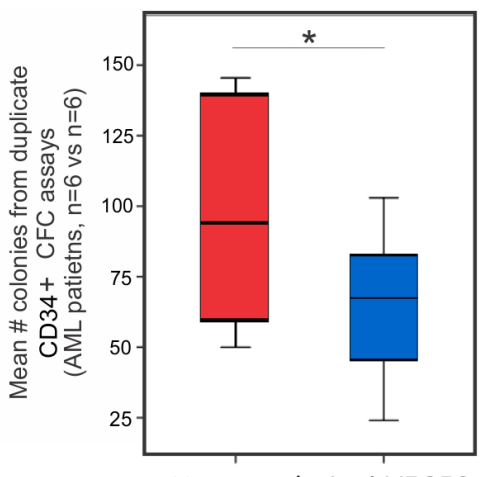

Untreated Anti-VEGFC

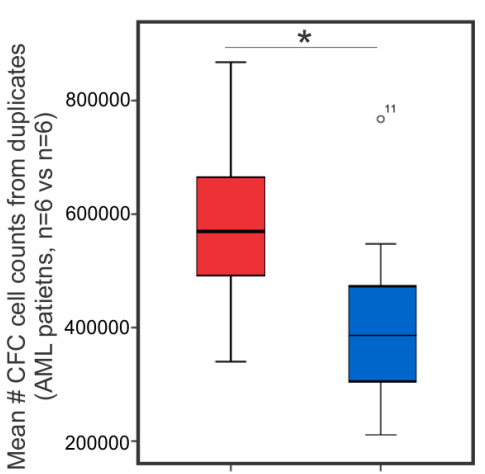

Untreated Anti-VEGFC
B

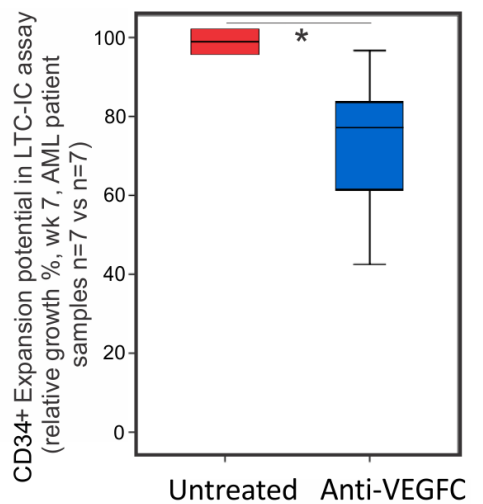

C

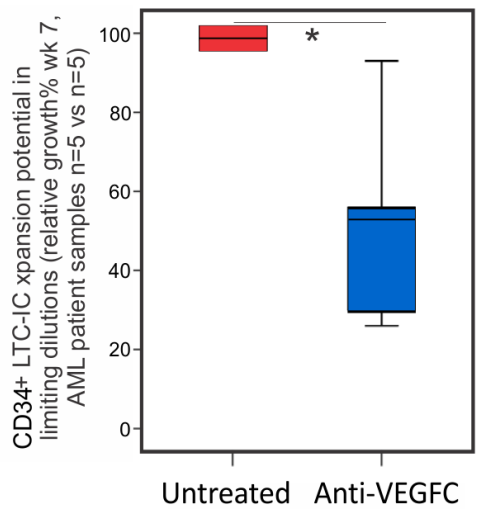

D

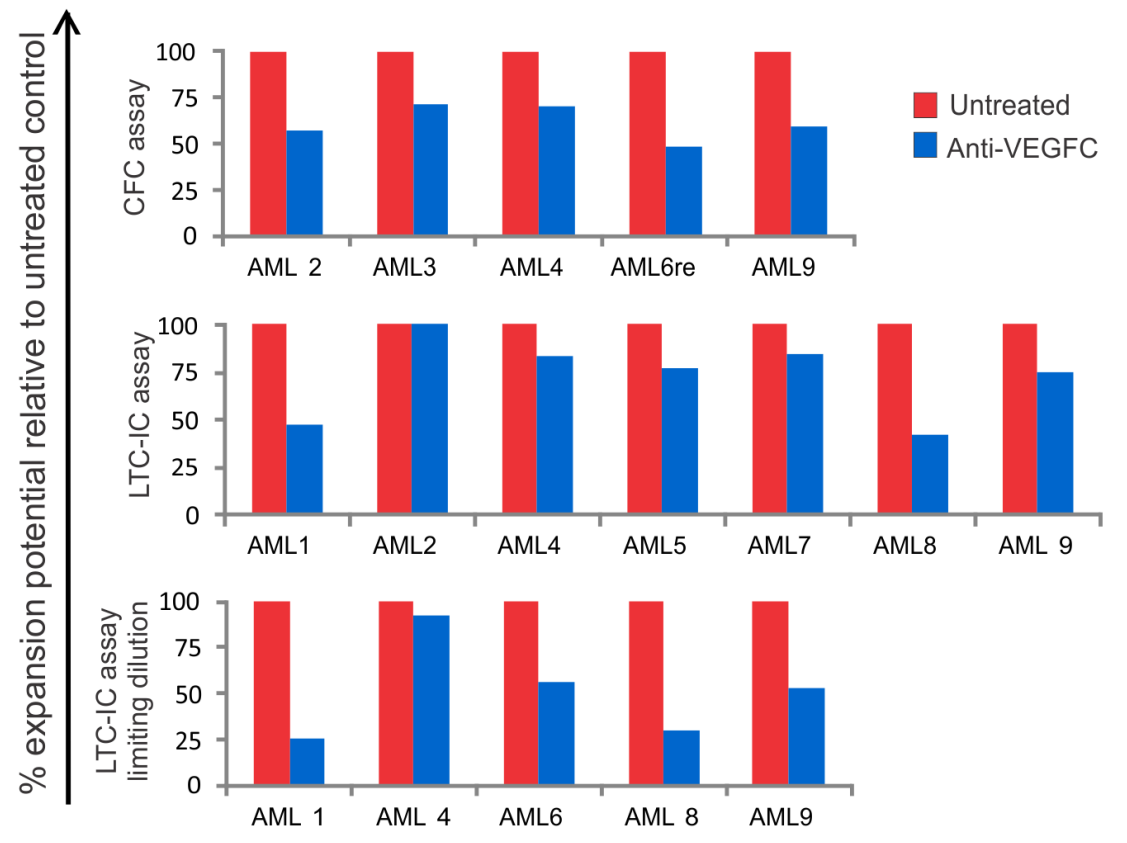

F

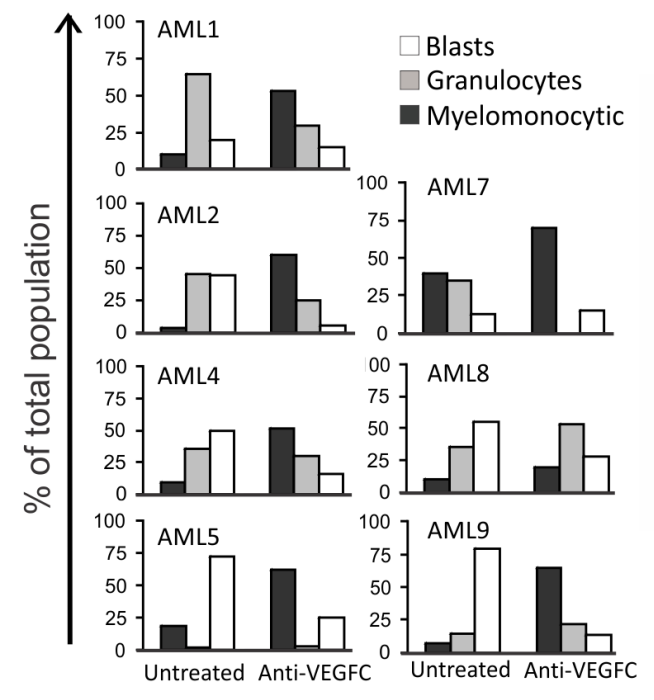

E
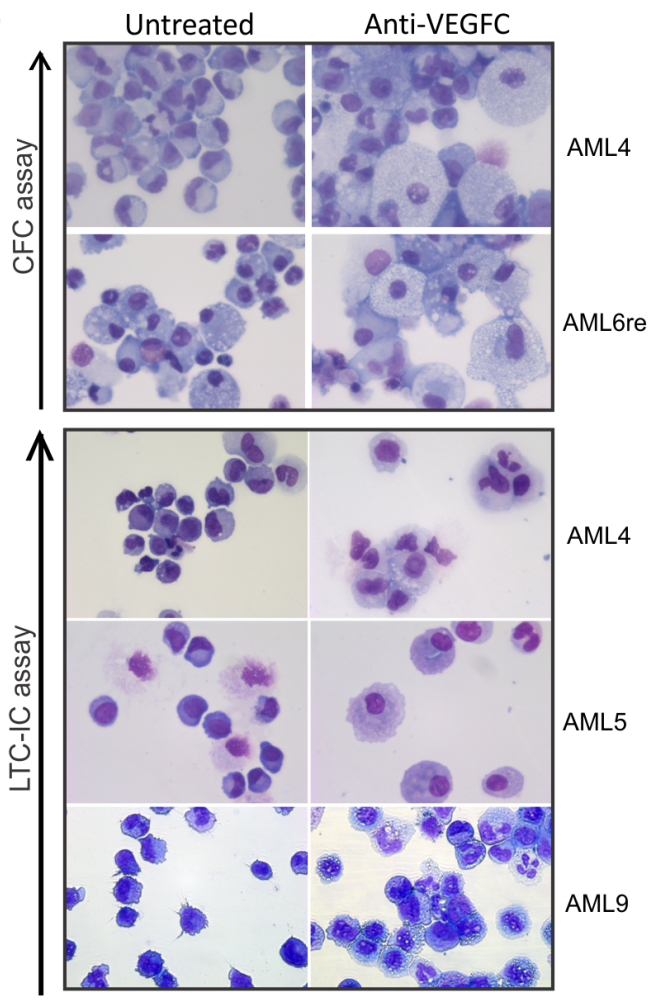

$\mathrm{H} \quad$ = Untreated $_{\text {Anti-V } \mathrm{EGFC}}^{\text {un }}$

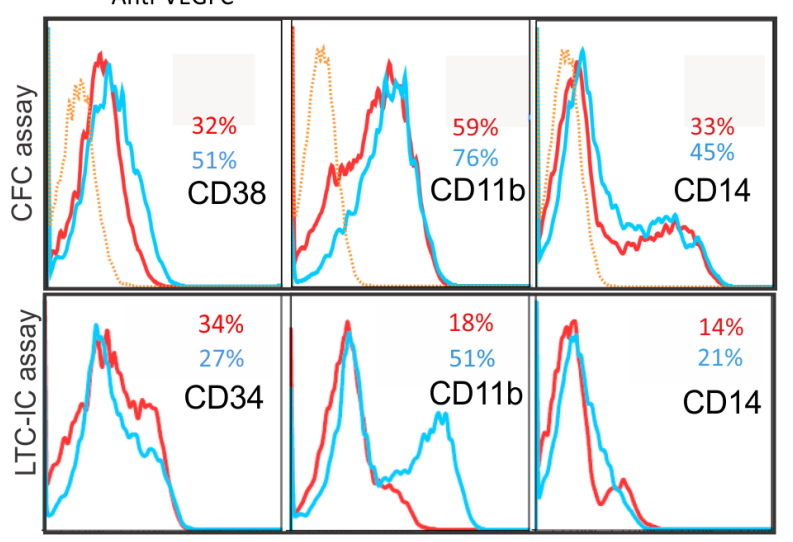

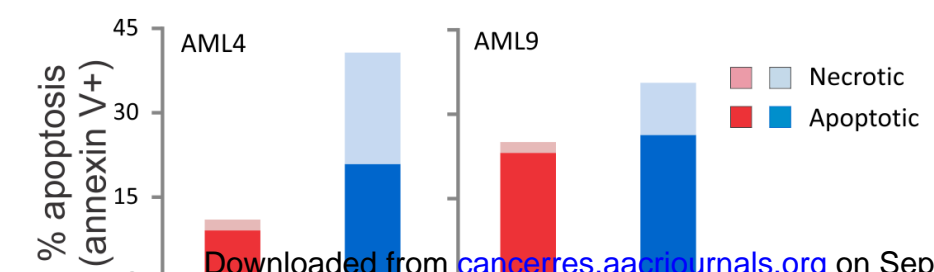

Downloaded from cancerres.aacrjournals.org on September 7, 2018. ( 2018 American Association for Cancer Research. 
Figure 3

A

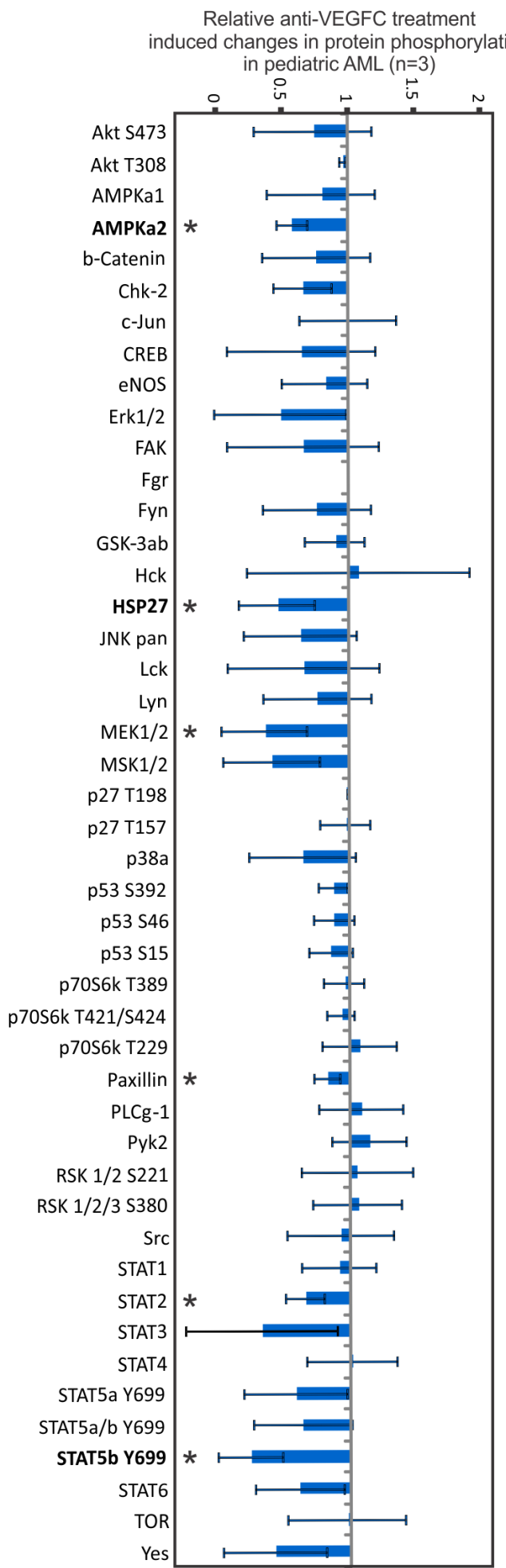

B
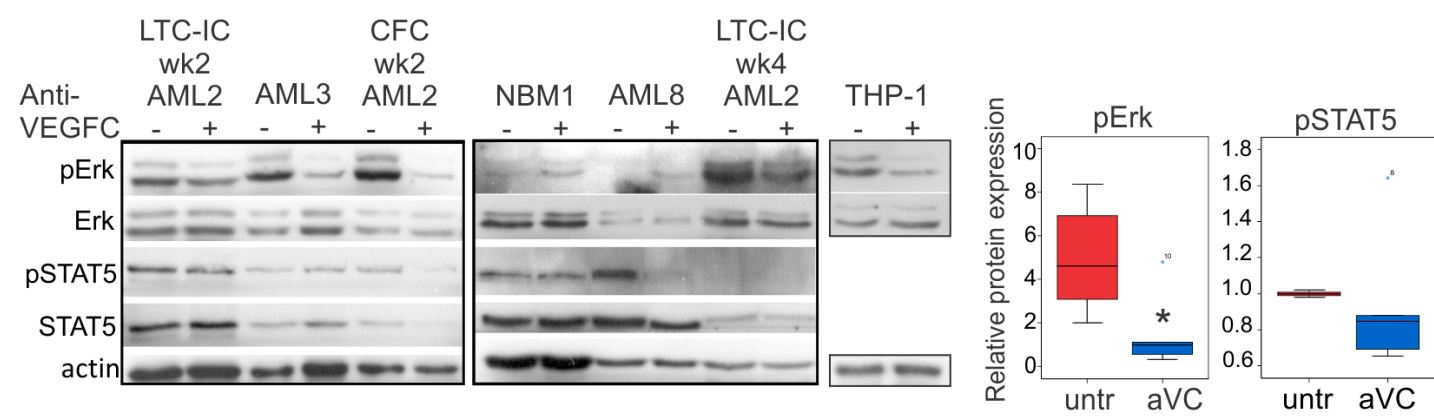

C

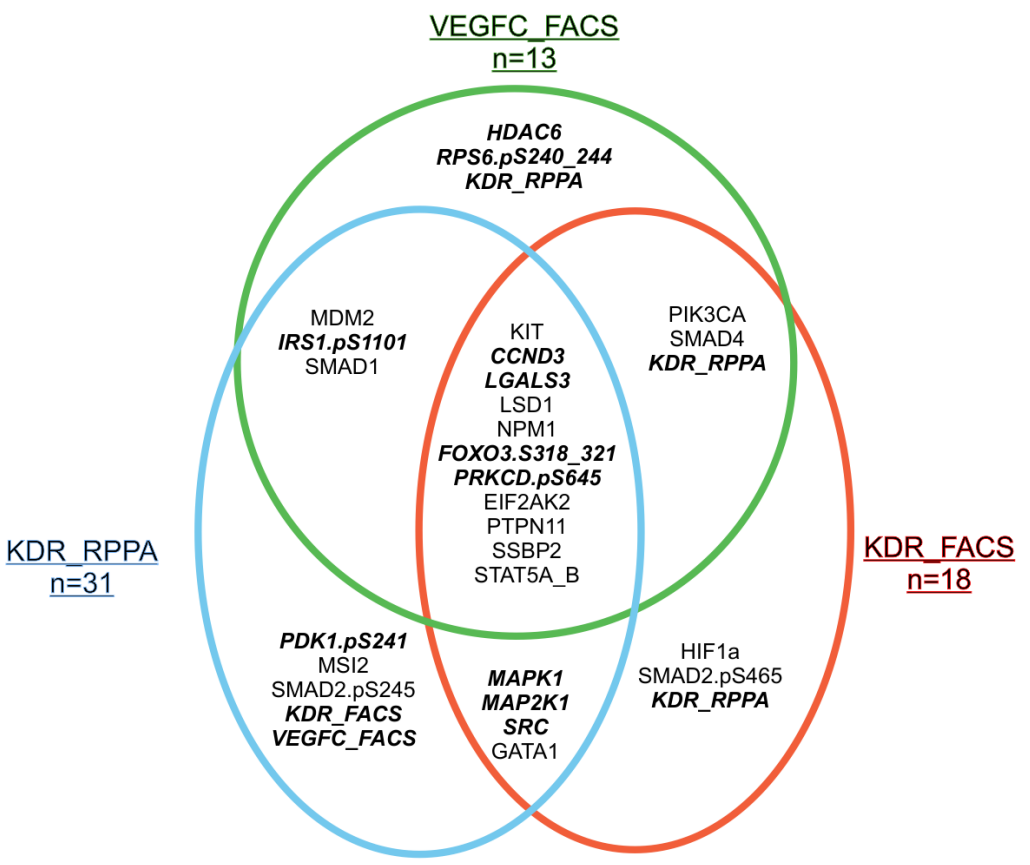

D

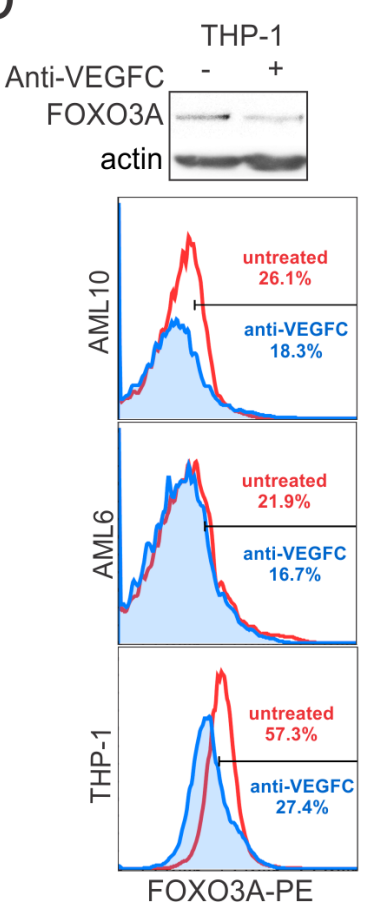

E
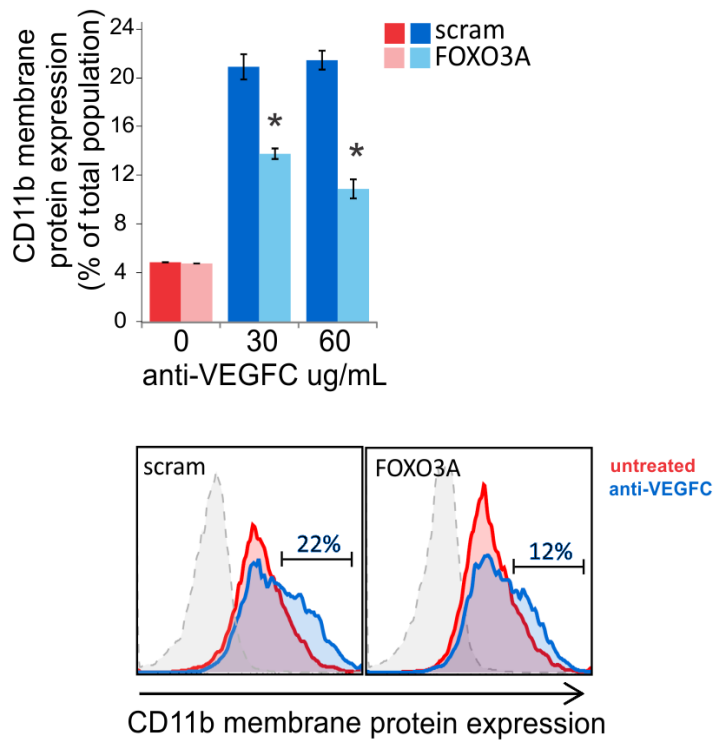
A
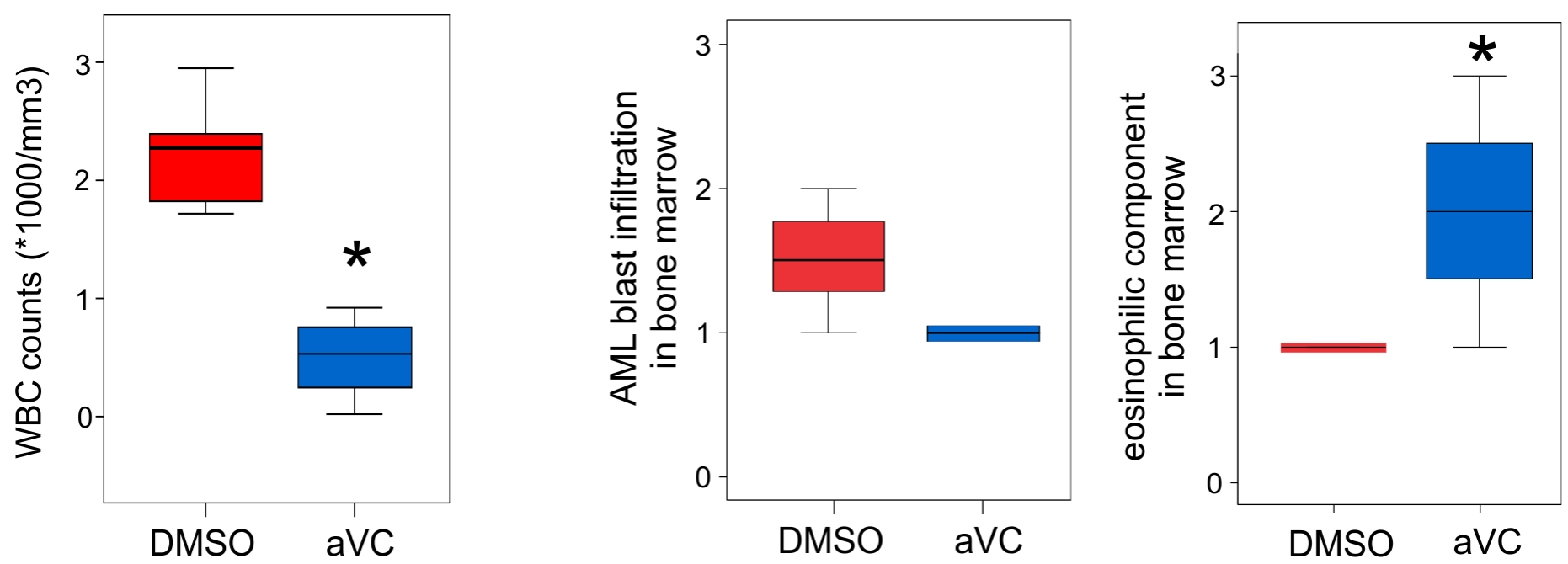

C
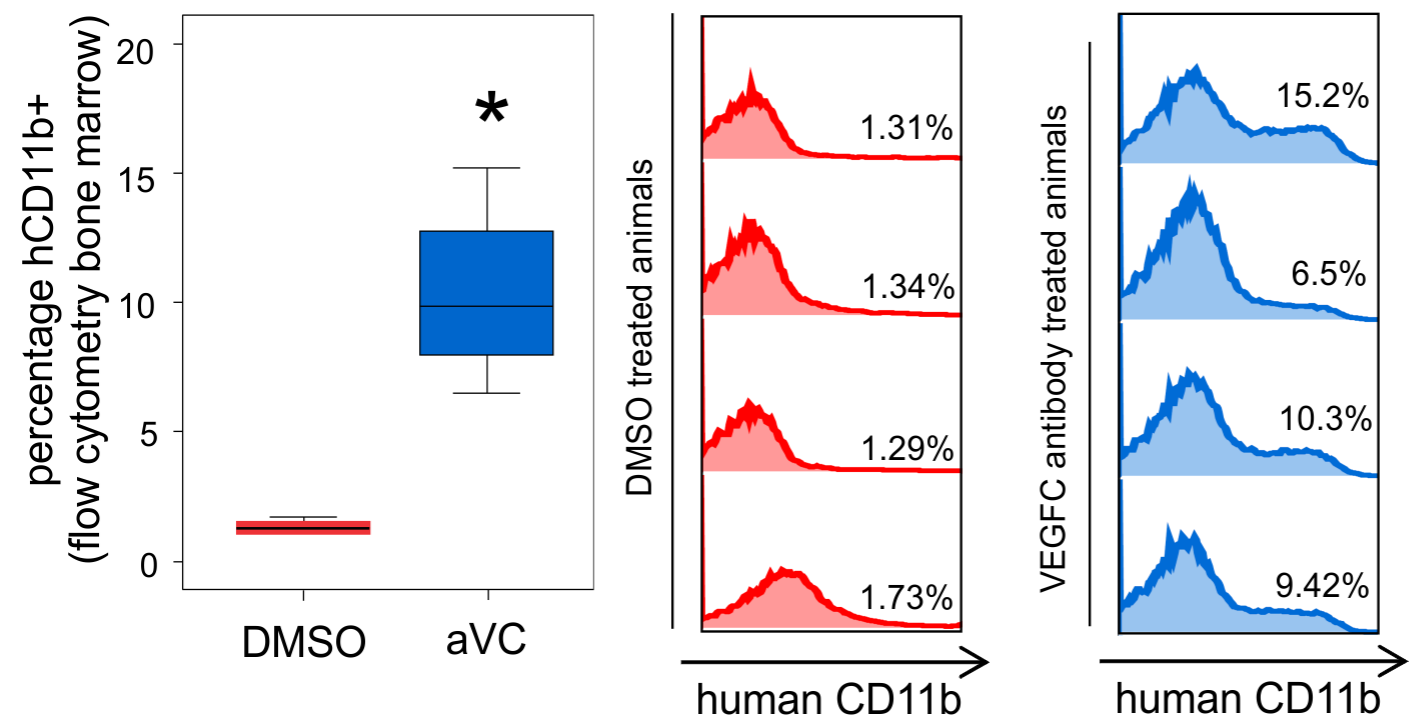

D
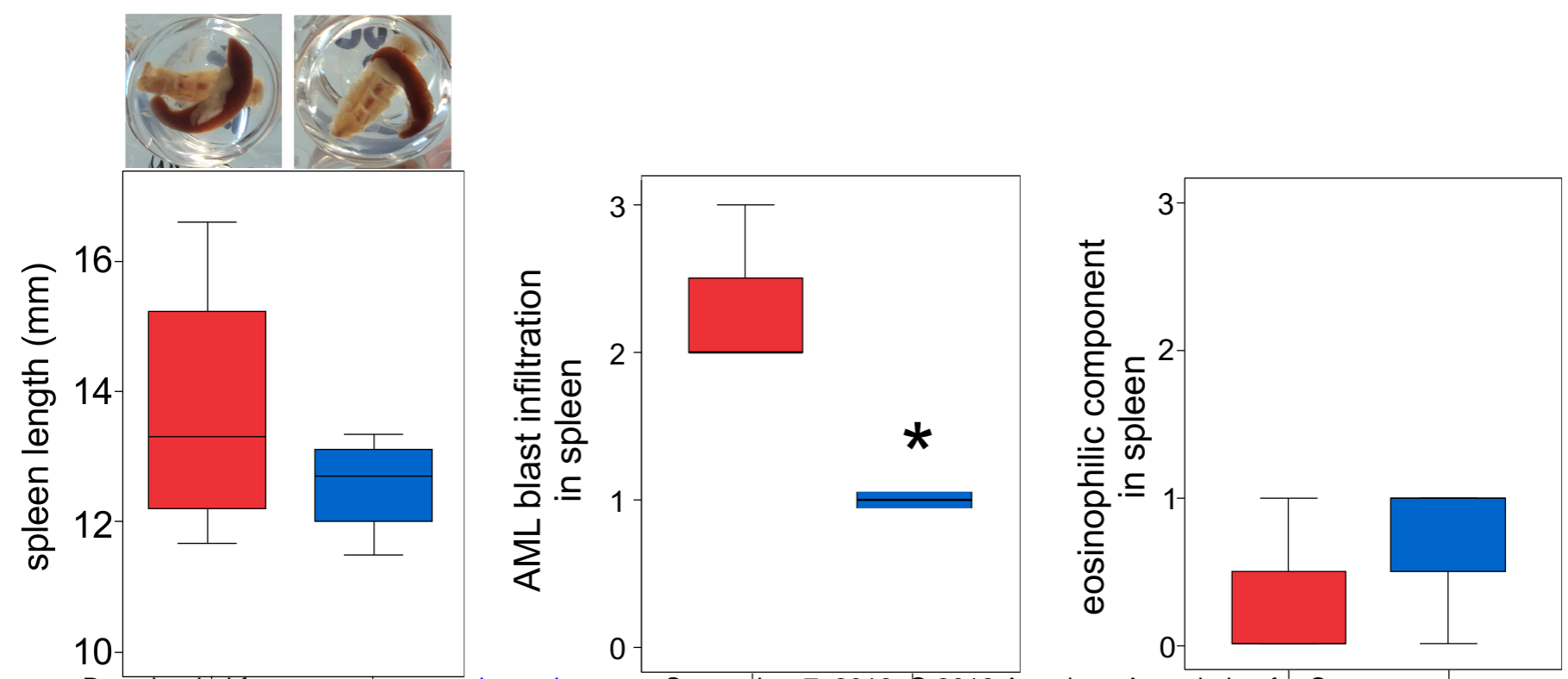

Downloaded from cancerres.aacrjournals.org on September 7, 2018. (0) 2018 American Association for Cancer
DMSO aVC aVS 


\section{Cancer Research}

A.CR $\begin{gathered}\text { American Association } \\ \text { for Cancer Research }\end{gathered}$

\section{VEGFC antibody therapy drives differentiation of AML}

Kim R Kampen, Frank J.G. Scherpen, Hasan Mahmud, et al.

Cancer Res Published OnlineFirst September 5, 2018.

Updated version Access the most recent version of this article at: doi:10.1158/0008-5472.CAN-18-0250

Supplementary Access the most recent supplemental material at:

Material http://cancerres.aacrjournals.org/content/suppl/2018/09/05/0008-5472.CAN-18-0250.DC1

Author Author manuscripts have been peer reviewed and accepted for publication but have not yet Manuscript been edited.

E-mail alerts Sign up to receive free email-alerts related to this article or journal.

Reprints and To order reprints of this article or to subscribe to the journal, contact the AACR Publications Subscriptions Department at pubs@aacr.org.

Permissions To request permission to re-use all or part of this article, use this link http://cancerres. aacrjournals.org/content/early/2018/09/05/0008-5472.CAN-18-0250.

Click on "Request Permissions" which will take you to the Copyright Clearance Center's (CCC) Rightslink site. 